important role of similar case reports in establishing a better understanding of this problem and how best to deal with it.

\section{References}

1. Leyh RG, Kofidis T, Fischer S, Kallenbach K, Harringer W, Haverich

A. Aortic root reimplantation for successful repair of an insufficient pulmonary autograft valve after the Ross procedure. $J$ Thorac Cardiovasc Surg. 2002;124:1048-9.

2. Masetti P, Davila-Roman VA, Kouchoukos NT. Valve-sparing procedure for dilatation of the autologous pulmonary artery and ascending aorta after the Ross operation. Ann Thorac Surg. 2003;76:915-6.

3. Ishizaka T, Devaney EJ, Ramsburgh SR, Suzuki T, Ohye RG, Bove EL. Valve sparing aortic root replacement for dilatation of the pulmonary autograft and aortic regurgitation after the Ross procedure. Ann Thorac Surg. 2003;75:1518-22.

\title{
A giant pleural fibrous tumor
}

\author{
Heyman Luckraz, FRCS, ${ }^{\text {a }}$ Saima Ehsan, MBBS, ${ }^{a}$ Allen R. Gibbs, FRCPath, ${ }^{b}$ and \\ Eric G. Butchart, FRCS, ${ }^{a}$ Cardiff, United Kingdom
}

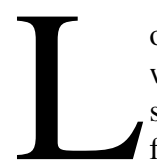
ocalized (solitary) fibrous tumors of the pleura (LFTPs) were first described as a separate entity in $1931,{ }^{1}$ despite having first been reported in $1870 .^{2}$ They represent fewer than $5 \%$ of pleural neoplasms, with a prevalence of approximately 2.8 cases per 100,000 hospital patients. Immunohistochemical analysis has confirmed these tumors to be nonmesothelial in origin. ${ }^{3}$ They arise from either visceral or parietal pleura and may undergo malignant transformation (as many as $12 \%$ of cases). ${ }^{4}$

Symptoms such as dyspnea, cough, chest pain, arthritic pain, finger clubbing, and hypoglycemia (from production of insulinlike growth factors) are present in 50\% of cases, whereas the remainder are discovered incidentally. The heaviest LFTP described to date weighed 1850 g. ${ }^{5}$ We describe a case of an LFTP that enlarged at an average rate of $10 \mathrm{~g} / \mathrm{month}$ during a period of 16 years.

\section{Clinical Summary}

A 67-year-old woman was referred with a left pleural spaceoccupying lesion (Figure 1). She had undergone investigations 16 years before this episode, with an incidental finding of a shadow in the left oblique fissure on chest radiography. Computed tomographic (CT) scan with biopsy favored a diagnosis of loculated fluid collection in the fissure. Unfortunately, the patient was unavailable for follow-up after that, until she was seen recently after development of finger clubbing, mild breathlessness, left-sided chest pain, and dry cough.

\footnotetext{
From the Cardiothoracic Unit and the Histopathology Department, University Hospital of Wales, Cardiff, United Kingdom.

Received for publication Jan 22, 2005; revisions received Feb 22, 2005; accepted for publication April 5, 2005.

Address for reprints: Heyman Luckraz, FRCS, Cardiothoracic Unit, Block C5, University Hospital of Wales, Heath Park, Cardiff CF14 4XN, UK (E-mail: HeymanLuckraz@aol.com).

J Thorac Cardiovasc Surg 2005;130:1216-7

$0022-5223 / \$ 30.00$

Copyright $\odot 2005$ by The American Association for Thoracic Surgery

doi:10.1016/j.jtcvs.2005.04.035
}

The patient had clinical signs of pleural effusion, but a pleural tap was dry. CT revealed a large lesion occupying the left pleural cavity. CT-guided biopsy revealed fibrotic tissue, with multifocal areas of fibroblastic reaction and associated mild lymphohistiocytic perivascular infiltrate. The appearances were considered nondiagnostic. She therefore underwent exploratory left thoracotomy, which revealed a gigantic lobulated mass $(23 \times 20 \times 16 \mathrm{~cm})$, separate from the usual left intrathoracic structures (Figure 2). There were two main vascular pedicles, one arising from the oblique fissure and the other from the pleural surface of the left hemidiaphragm. There were several other minor vascular pedicles. The main vascular pedicles were ligated with nonabsorbable ties (2-0 silk), whereas the minor ones were either ligated or occluded by diathermy. The mass weighed $1998 \mathrm{~g}$.

Macroscopic examination showed a smooth-surfaced, nodular, gray tumor, which on cut section was solid and revealed a gray, yellow, and brown variegated appearance with areas of necrosis. Spindle-shaped cells with hemangiopericytic, patternless, and hyaline areas were identified on histologic examination, in keeping with a diagnosis of solitary fibrous tumor. No features of malignancy were seen on light microscopy, despite extensive sampling. Specifically, mitotic rate was less than 1 per 10 high-power fields.

The patient made an uneventful postoperative recovery. She was discharged home on the sixth postoperative day.

\section{Discussion}

Resection of LFTP represents a small percentage of thoracic surgical activity $(<1 \%)$. Two interesting presenting symptoms of LFTP include finger clubbing and hypoglycemia. Hypertrophic osteoarthropathy is present in a fifth of patients, resulting from abnormal production of hyaluronic acid by tumor cells. ${ }^{5}$ The production of insulinlike growth factor 2 accounts for the hypoglycemic events (4\% of patients) and also impairs the growth hormone counterregulatory response to low blood sugar levels. ${ }^{5}$ These symptoms abate once the lesion has been completely excised.

Chest radiography and CT scanning with contrast remain the investigations of choice for LFTP. Pedunculated tumors show 


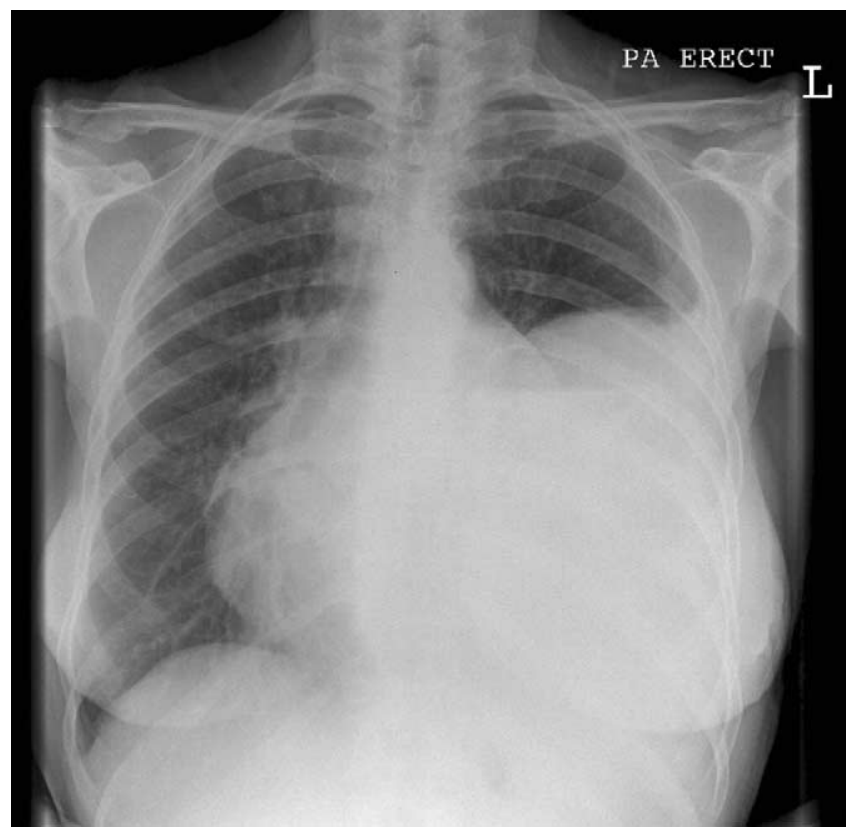

Figure 1. Chest radiograph of patient showing large spaceoccupying lesion in left pleural cavity.

marked mobility on fluoroscopy. Magnetic resonance imaging can be used to evaluate the fibrous nature of the tumor.

Although most of these tumors are benign, a clear resection margin at the time of surgery is the only guarantee of prevention of recurrences. If video-assisted thoracoscopic surgical technique is used, spillage of tumor cells should be avoided, especially when the mass is being removed from the pleural space.

Macroscopically, the tumor in our case showed mainly benign features, being well circumscribed, smooth, and pedunculated, although large size and areas of necrosis did suggest possible malignancy. ${ }^{4}$ Under light microscopy, the tumor lacked features suggestive of malignancy: high cellularity, cellular atypia, and high mitotic rate.

Although LFTPs have previously been described as localized mesotheliomas, it now been proved that LFTP is nonmesothelial in origin. Immunocytochemical analysis has shown LFTPs to be

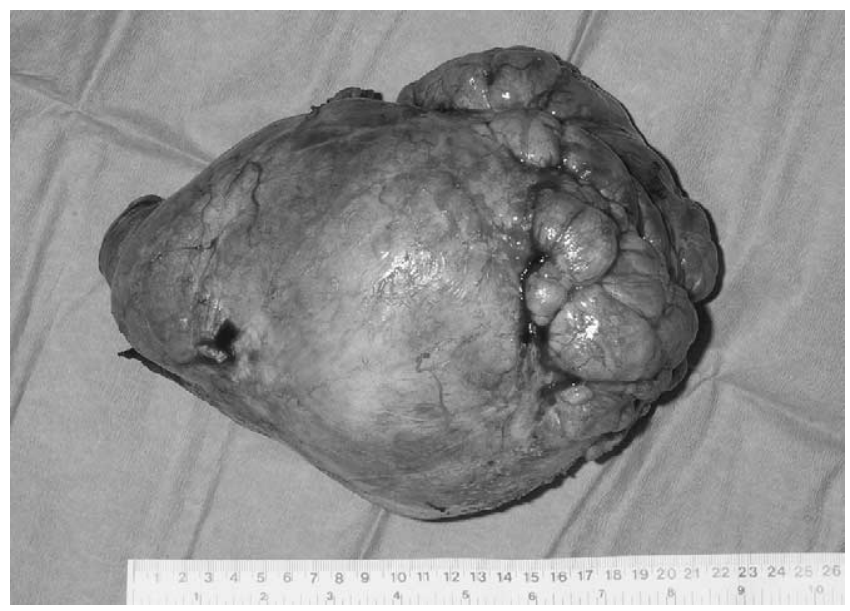

Figure 2. Photograph of LFTP immediately after excision.

cytokeratin negative but both vimentin and CD34 positive. ${ }^{3}$ Moreover, there is no correlation with asbestos exposure.

Both visceral and parietal pleura can be sites of origin for LFTP. The latter site is more difficult to treat, because the tumor may invade the chest wall, necessitating chest wall resection to achieve completeness of resection. Postoperative chemotherapy and radiotherapy have not been shown to provide any additional benefit. However, long-term follow-up ( $>10$ years) is vital to detect recurrences early.

\section{References}

1. Klemperer P, Rabin CB. Primary neoplasms of the pleura. A report of five cases. Arch Pathol. 1931;11:385-412.

2. Wagner E. Das tuberkelähnliche lymphadenom (Der cytogene oder reticulirte Tuberkel). Arch Heilk (Leipzig). 1870;11:497.

3. Hanau CA, Miettinen M. Solitary fibrous tumor: histological and immunohistochemical spectrum of benign and malignant variants presenting at different sites. Hum Pathol. 1995;26:440-9.

4. England DM, Hochholzer L, McCarty MJ. Localized benign and malignant fibrous tumor of the pleura. Am J Surg Pathol. 1989;13:640-58.

5. Cardillo G, Facciolo F, Cavazzana AO, Capece G, Gasparri R, Martelli M. Localized (solitary) fibrous tumors of the pleura: an analysis of 55 patients. Ann Thorac Surg. 2000;70:1808-12. 